\title{
Proximal Focal Femoral Deficiency
}

\author{
Vishal Kalia, Vibhuti
}

\begin{abstract}
Proximal focal femoral deficiency (PFFD) is a developmental disorder of the proximal segment of the femur and of acetabulum resulting in shortening of the affected limb and impairment of the function. It is a spectrum of congenital osseous anomalies characterized by a deficiency in the structure of the proximal femur. The diagnosis is often made by radiological evaluation which includes identification and description of PFFD and evaluation of associated limb anomalies by plain radiographs. Contrast arthrography or Magnetic Resonance Imaging is indicated when radiological features are questionable and to disclose the presence and location of the femoral head and any cartilagenous anlage. The disorder is more commonly unilateral and is apparent at birth. However, bilateral involvement is rarely seen. Therapy of the disorder is directed towards satisfactory ambulation and specific treatment depending on the severity of dysplasia.

Keywords

Proximal focal femoral deficiency, Plain radiograph, Congenital osseous anomaly
\end{abstract}

\section{Introduction}

Proximal focal femoral deficiency (dysgenesis of proximal femur or congenital short femur) is a rare congenital osseous anomaly manifested by failure of normal development of a variable portion of proximal femur(1). The bony defect denotes the entity as a femoral deficiency, and this focal lesion always involves the proximal segment of the femur. Total femoral agenesis and phocomelia are not included in this entity $(1,2)$. Coxa vara may be included in PFFD only if there is a true congenital shortening of the shaft present at birth, as well as neck shaft varus(1).

The aetiology is unknown and no familial or sexual predilection has been recognized.3 Various theories have been proposed. Some postulated that the malformation is due to cellular nutritional disturbance at the time of cell division (at four to six weeks after ovulation). Others postulated a local vascular damage to mesenchymal tissue and some others proposed intrauterine compression of the thigh at time of femoral diaphysis ossification. Heredity does not seen to play a major role $(1,4)$.
Proximal focal femoral deficiency usually is unilateral but is reported to occur bilaterally in as many as $30 \%$ of affected individuals. Proximal focal femoral deficiency is almost always an isolated occurrence. However, it may be associated with other skeletal abnormalities like ipsilateral fibular hemimelia (most commonly associated), caudal dysplasia, caudal regression syndrome, lumbosacral spine deformities especially in infants of diabetic mothers. Associated skeletal abnormalities may be detected in approximately half the unilateral cases and $85 \%$ with bilateral involvement $(1,3)$.

Case

A four year old male child presented with gait disorder and shortening of the proximal part of both lower limbs since birth. General physical examination was normal except that the child's height is small for age with shortening of both femurs. The child has a broad based gait and moves in short steps with persistent flexion at the hips and knees simulating squatting position. No other significant clinical history was present. Laboratory tests were essentially within normal limits. Plain radiograph of

From the Department of Radiodiagnosis, Dayanand Medical College \& Hospital, Ludhiana

Correspondence to : Dr. Vishal Kalia, 464-Sector 8/II, Urban Estate, Karnal, Haryana. 
Table 1: Classification of PFFD (Adapted from Aitken)

\begin{tabular}{|c|c|c|c|}
\hline $\begin{array}{l}\text { Head of } \\
\text { femur }\end{array}$ & Acetabulum & Femoral segment & $\begin{array}{l}\text { Relationships among } \\
\text { components of femur } \\
\text { and acetabulum at } \\
\text { skelektal maturity }\end{array}$ \\
\hline Present & Adequate & Short & $\begin{array}{l}\text { Bony connection } \\
\text { between components of } \\
\text { femur; } \\
\text { Head of acetabulum } \\
\text { Subtrochanteric varus, } \\
\text { often with } \\
\text { pseudarthrosis }\end{array}$ \\
\hline Present & $\begin{array}{l}\text { Adequate or } \\
\text { moderately } \\
\text { dysplastic }\end{array}$ & $\begin{array}{l}\text { Srort; } \\
\text { Usually proximal } \\
\text { bony tuft }\end{array}$ & $\begin{array}{l}\text { No osseous connection } \\
\text { between head and shaft; } \\
\text { Head in acetabulum }\end{array}$ \\
\hline $\begin{array}{l}\text { Absent or } \\
\text { represented } \\
\text { by ossicle }\end{array}$ & $\begin{array}{l}\text { Severely } \\
\text { dysplastic }\end{array}$ & $\begin{array}{l}\text { Short; } \\
\text { Usually } \\
\text { proximally } \\
\text { tapered }\end{array}$ & $\begin{array}{l}\text { May be osseous } \\
\text { connection between } \\
\text { shaft and proximal } \\
\text { ossicle } \\
\text { No osseous connection } \\
\text { between femur and } \\
\text { acetabulum }\end{array}$ \\
\hline Absent & $\begin{array}{l}\text { Absent, } \\
\text { Obturator foramen } \\
\text { enlarged; } \\
\text { Pelvis squared in } \\
\text { bilateral cases }\end{array}$ & Short, deformed & \\
\hline
\end{tabular}

both the lower limbs showed shortening of the bilateral femora with thinning of both fibula. However, both femoral heads and acetabuli are well formed and femoral heads are seen well within the acetabuli (Fig. 1). No other skeletal deformities were seen in the bones of the upper limbs and spine. The child was referred to the orthopedic department for further management but the parents were not willing for any further treatment. This case report describes a rare case of bilateral proximal focal femoral deficiency in a four year old child but the patient was lost to follow up due to certain financial constraints and unwillingness of parents for any surgical intervention.

\section{Discussion}

The diagnosis of proximal focal femoral deficiency in a young child, which can be difficult by clinical examination, is often made by radiological examination. A radiological classification proposed by Aitken is employed most widely both in diagnosis and therapeutic planning(5). This classification arbitrarily divides the disorder into four classes (Table 1) but does not permit simple categorization of an individual case.

When the radiological features are questionable, arthrography may be of help in establishing the degree of severity of malformation, especially during the first two years of life. Imaging with magnetic resonance may offer a means of demonstrating the entire disorder more effectively including any cartilaginous anlage and the status of hip joint.

The differential diagnosis in infancy includes septic arthritis and congenital dislocation of the hip in which the femur length is normal with lateral displacement of the shaft. The differential diagnosis for congenital coxa vara can be made by noting the apex of the deformity. Apex of the deformity is in subtrochanteric region above or at the level of the acetalulum in PFFD and is in the femoral head in congenital coxa vara with decreased neck shaft angle (below $140^{\circ}$ ) in the newborn(1).

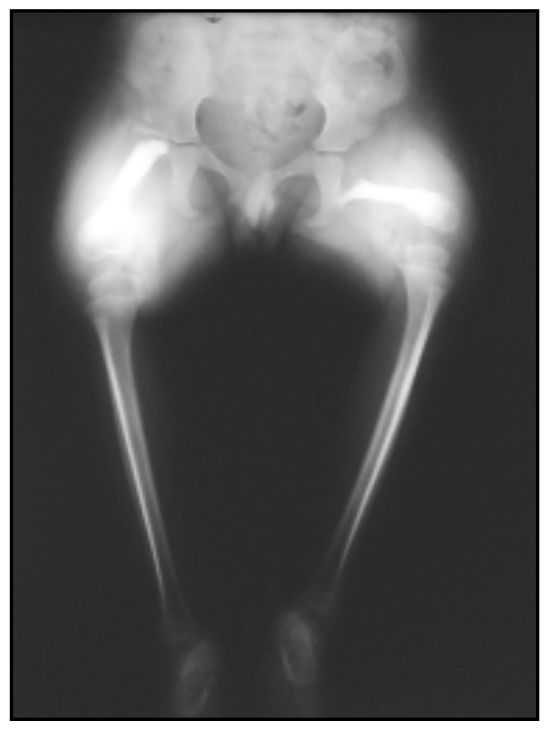

Fig. 1: Plain X-ray of both lower limbs showing shortening of the bilateral femora with thinning of both fibula.

Therapy is directed towards early and satisfactory ambulation and specific treatment depending on the severity of dysplasia. Therapeutic measures include fusion, osteotomy, leg-lengthening procedures and amputation followed by the use of a prosthesis.

\section{References}

1. Levinson ED, Ozonoff MB, Royen PM. Proximal femoral focal deficiency (PFFD). Radiology 1977; 125: 197-203.

2. Amstutz HC, Wilson PD Jr. Dysgenesis of the proximal femur (coxa vara) and its surgical management. J Bone Joint Surg 1962; 44A: 1-24.

3. Jacbson HG, Murray RO, Stoken DJ. Proximal focal femoral deficiency. In: Jacobson HG, ed. Radiology of skeletal disorders. Churchill Livingston, London 1990. pp. 37.

4. Shands AR Jr, Mac Ewen GD. Congenital abnormalities of femur. Acta Orthop Scand 1962; 32: 307-14.

5. Aitken GT. Proximal femoral focal deficiency. Definitions, classification and management. [In]: Aitken GT ed: proximal focal femoral deficiency, a congenital anomaly. A symposium, Washington DC, National Academy of Sciences, 1968. 